\title{
NOTA SOBRE LA INSCRIPCIÓN LATINA DEL ARA VOTIVA A «ERUDINO» DE LA CANTABRIA ROMANA
}

\author{
POR \\ LUIS JENARO MACLENNAN \\ C/o Trinity College, Oxford
}

\section{RESUMEN}

Se descarta la datación consular de la inscripción en cuanto no apropiada al contexto. Las serias dificultades que presenta la lectura tradicional del epígrafe la hacen inverosímil. Se subraya el interés de la fecha de la dedicatio, coincidente con Neptunalia.

\section{SUMMARY}

The consular dating is to be rejected as inappropriate within its context. The serious difficulties that the traditional resolution of abbreviations presents make it unlikely as such. Emphasis is placed on the date of the dedicatio and the Neptunalia.

Con motivo de un trabajo de investigación relacionado con el latín de Cantabria y la población epigráfica indígena, tuvimos recientemente ocasión de estudiar con especial interés los diversos problemas que esta célebre inscripción venía suscitando y que habían sido insuficientemente analizados ${ }^{1}$. Dichos problemas rebasaron con creces el tema lingüístico y onomástico inicialmente propuesto. El resultado fue una nota enviada a $A E s p A$ en la que dábamos por supuesto la validez de la lectura tradicional del epígrafe y consiguiente resolución de abreviaturas, situándonos, por tanto, en 399 d.C.:

\section{CORNE(lius) VICANVS / AVNIGAINV $(m)$ /}

$\operatorname{CESTI}(i) \mathrm{F}($ ilius $) . \operatorname{ARA}(m) /$ POSSVIT.

DEO / ERVDINO. X. K(alendas)/

AVGV(stas). MA(llio). EV(tropio)

$\mathrm{CO}(n) \mathrm{s}(u l i b u s)$

1 Es la estela $n^{\circ} 84$ en J. L. Iglesias Gil, Epigrafía cántabra, Santander, 1976, donde puede verse la bibliografía anterior a esa fecha; vid. especialmente M. Vigil, Sobre los orígenes sociales de la Reconquista, Barcelona, 1974, 28-32, 181-188 y, entre otros, A. Montenegro Duque et alii, España romana, Madrid, 1986, 377.
Expresábamos en dicha nota cierta perplejidad ante la datación consular, dado el contexto, y hacíamos hincapié en dos anomalías: 1) el consulado de Eutropio no fue reconocido nunca en occidente; 2) se incurre en una desviación del estilo de datación imperial según el formulismo del Codex Th. en cuanto que en la inscripción se menciona al cónsul de occidente por su nomen en vez del cognomen. Atribuíamos la mención de Eutropio a un posible error de oficio, dado el alejamiento de la zona y el ambiente de gran confusión reinante por entonces. En cuanto a la segunda anomalía, quizás habría que ver en ella una peculiaridad de la fórmula onomástica indígena subyacente, con sentido distinto del nombre «individual».

Partiendo de dicha lectura del epígrafe, tal explicación no sólo era plausible sino la más satisfactoria de cuantas habíamos considerado.

Habiendo tenido noticia ${ }^{2}$ con posterioridad de que los supuestos nombres de los cónsules habían sido recientemente descartados en una conferencia de A.U. Stylow, en el Instituto Arqueológico Alemán de Madrid, con propuesta de nueva lectura, volvimos a examinar la cuestión partiendo esta vez de un elemento de duda introducido sobre la validez de la resolución tradicional de abreviaturas del epígrafe - validez que no habíamos cuestionado por la inercia que confieren casi tres cuartos de siglo repitiendo lo mismo-.

En efecto, dicha lectura es considerada «imposible» en una breve nota del apéndice crítico de $C L R E^{3}$, la cual había escapado a nuestra atención y

${ }^{2}$ Mediante información amablemente suministrada por $\mathrm{J}$. Arce, a quien expresamos aquí nuestro reconocimiento por habernos precavido a tiempo. La cuestión fue estudiada de nuevo y el trabajo reescrito. La primera versión fue realizada en la Sterling Library de la Universidad de Yale (EE.UU.) en 1994; la presente en Oxford (abril-mayo 1996). En trabajos recientes se sigue dando todavía la lectura tradicional del epígrafe sin otro comentario (e.g. F.J. García de Castro, Sociedad y Poblamiento en la Hispania del siglo IV, Valladolid, 1995, 64, 311, 326).-CLRE es de 1987 (Atlanta, Georgia).

${ }^{3}$ 661-662, cuyas fuentes son J.M. Iglesias Gil, Onomástica prerromana en la epigrafía cántabra, Santander, 1974, 37 $\mathrm{n}^{\circ} 6$ y J. Vives, ILER. 
que suponemos es de donde parte A.U. Stylow ${ }^{4}$. Nos habíamos servido inicialmente de CLRE ad loc. sin prestar mayor atención ya que gran parte de los datos allí suministrados apoyaban nuestra argumentación, independientemente conducida, concentrándonos preferentemente en PLRE II por su riqueza de datos sobre las particularidades del consulado de Eutropio.

Las razones alegadas en CLRE para declarar «imposible» tal lectura y excluir la inscripción son el no reconocimiento de dicho consulado en occidente y el hecho de que en las inscripciones el cónsul $\mathrm{Fl}$. Mallius Theodorus nunca figura como $\mathrm{Ma}$ llius solamente, sino con nomen + cognomen o cognomen sólo. Son las mismas razones que señalábamos como anomalías de la inscripción en la nota previa y que tratábamos de explicar como queda indicado, con la única diferencia de que CLRE añade el testimonio de las inscripciones para la cuestión de la onomástica del cónsul de occidente y nosotros nos limitábamos a constatar la discrepancia respecto del estilo de la legislación imperial pertinente. De ambas la más seria es la segunda; pero ninguna es lo suficientemente fuerte en sí como para afirmar la imposibilidad de tal lectura, sino como poco probable o inverosímil. Hemos llegado a la conclusión de que la lectura es, en efecto, errónea; pero no exclusivamente por las razones dadas, cuya validez por separado no es categórica, sino porque la datación consular no encaja en un contexto epigráfico de esta índole, a lo que se suma, conjuntamente, la argumentación señalada. Las siguientes puntualizaciones deben ser tenidas en cuenta antes de que la cuestión de los supuestos nombres de los cónsules sea relegada a un plano de interés meramente académico.

\section{SOBRE EL CONSULADO DE EUTROPIO}

La cuestión central era saber si su nombre pudo figurar alguna vez en una lista de cónsules llegada a occidente. No basta con alegar el no reconocimiento por parte de occidente, a lo que se limita PLRE II ${ }^{5}$, omitiendo señalar que no fue proclamado - lo que nos indujo a no apreciar bien la situación en la nota previa-. El mero no reconocimiento, frecuentemente, como se indica en $C L R E^{6}$, no es

\footnotetext{
${ }^{4}$ En la conferencia aludida, de cuyo contenido no tenemos otra información que la indicada, y que debe de ser reciente ya que nada se indica al respecto en la $2^{\mathrm{a}}$ reimpresión de J. Arce, El último siglo de la España romana (284-409), Madrid, 1994, 143-144.

5 442-444.

6 24-26.
}

más que un indicio de malas relaciones, inferido a veces equivocadamente de la escasez de pruebas ${ }^{7}$. «Occidente», en este caso, significa Stilicho, parte interesada por su hostilidad y animadversión hacia Eutropio, y que rehusó varias veces reconocer a los cónsules proclamados por sus enemigos políticos, después de ascender al consulado en 400 d.C. en una época surcada de fricciones entre ambas mitades del Imperio ${ }^{8}$. La profusión de datos en CLRE ad loc. y la omisión mencionada en PLRE II oscurecen a veces la presentación de los hechos, nítidamente expresados en Degrassi, FCIR ad loc., donde queda señalado en la misma lista de cónsules por parejas, a diferencia de PLRE II ${ }^{9}$, que el consulado de Eutropio no fue hecho público en occidente, cesando también en oriente el 17 agosto 399 en virtud de anulación por decreto. De esta fecha arranca su damnatio memoriae y la caída efectiva del poder en el otoño de dicho año. Del 1 de enero al 17 de agosto queda suficiente margen de tiempo para hacer posible que el nombre del cónsul elegido se hubiera deslizado en una lista enviada a occidente quizás a principios del consulado, en espera de proclamación, y que no se hubiese rectificado después ${ }^{10}$. Indicábamos esta posibilidad en nuestra nota previa.

De la época temprana del consulado de Eutropio no sabemos nada; menos aún de la acogida que pudo dispensarse en Hispania a la turbulencia de los acontecimientos cuya noticia no se haría oír sin retraso - razón por la que no parece verosímil que semejante datación consular se hubiese llevado materialmente a cabo después del primero de enero del 400 cuando Stilicho era ya cónsul de occidenteDe no ser por el papiro 16.VIII no sabríamos que el consulado de Eutropio fue proclamado en Egipto ${ }^{11}$. No cabe esperar que en zonas remotas de occidente se procediese con el rigor y maestría de los escribas de Egipto en la diseminación de fórmulas para la promulgación oficial de los nuevos cónsules del año ${ }^{12}$. Dichos escribas, que no eran funcionarios del estado, verificarían las fórmulas ante un oficial del gobierno ${ }^{13}$. El mismo procedimiento valdría para el lapicida de la inscripción cántabra, pero con resultados de menor precisión. La transmisión textual de

\footnotetext{
7 ibid.

8 Jones, LRE, I, 182 ss.; CLRE, 16, 25, passim.

91242 ss.

10 Como la proclamación era imprescindible para entrar en funciones (RuDiz, II.1, 827), el cumplimiento del requisito sería presumiblemente anterior al 1 de enero del 400; sobre la proclamación por separado en cada parte, vid. CLRE,

1 CLRE, ad loc. (399)

2 CLRE, 26.

13 ibid.
} 16. 
los Fasti cons. (historiográficos) da testimonio de tachaduras y rectificaciones en el caso de los cónsules del $399^{14}$. En rigor la datación para el 399 d.C. debería ser post consulatum (i.e., p.c. Honori IIII et Eutychiani), o por un cónsul solamente ${ }^{15}$.

\section{SOBRE LA NOMENCLATURA DEL CÓNSUL Fl. MALLIUS THEODORUS}

La argumentación más fuerte contra la validez de la lectura tradicional del epígrafe la constituye el testimonio de las inscripciones aducido en $C L R E$, que viene a sumarse al de la legislación imperial que habíamos observado por nuestra cuenta: no se da el caso de que aparezca mencionado por el nomen solo, sino por el cognomen o por ambos. Cabe señalar, sin embargo, que entre las fórmulas de la eponimia figura el uso del gentilicio de un cónsul y el cognomen del otro ${ }^{16}$, aunque dicha fórmula requiere el uso de et: Sal(vio) et Torq(uato) co(n)s(ulibus) (CIL, XV 733, 148 d.C.). Por otra parte, en el supuesto de que la inscripción de Cantabria fuese del 399 d.C., cabría albergar alguna duda sobre la interpretación por parte del lapicida o del dedicante del nombre «diacrítico» ${ }^{17}$ ante una nomenclatura como $\mathrm{Fl}$. Mallius Theodorus. Lo tardío de la fecha y el subyacente indigenismo ${ }^{18}$ habrían podido quizá favorecer Mallius como término «marcado» de dicha nomenclatura, componente, por otra parte, bien asegurado como parte del nombre no sólo en incripciones del oeste sino en la tradición literaria (S. Agustín, Claudiano) ${ }^{19}$.

\section{NOMENCLATURA DEL DEDICANTE. FECHA E ÍNDOLE DE LA INSCRIPCIÓN}

Vicanus es el cognomen ${ }^{20}$ cuya adquisición puede constituir la razón de ser del ara votiva en reco-

\footnotetext{
14 CLRE, ad loc.

15 En occidente se databa mayoritariamente por un solo cónsul, CLRE, 25; vid. también R. Cagnat, Cours d'Épigraphie latine, Paris, 1914, 254; RE, IV, 1135-1136.

16 RuDiz, II, 1, 709 cita varios casos.

17 Vid. A. Cameron, «Polynomy in the Late Roman Aristocracy: The Case of Petronius Probus», JRS, 75, 1985, 164182, 171-174 especialmente.

18 Para situación análoga en Dalmacia cf. Alföldy, Latomus, 25, 1966, p. 41. Por otra parte, el uso de gentilicia como cognomina (i.e., nombre «individual») era muy frecuente en el imperio.

19 PLRE, I, 900

20 I. Kajanto, The Latin Cognomina, Helsinki, 1965 (Commentationes Humanarum Litterarum, XXXVI, 2. Societas Scientiarum Fennica), 311, señala Vicanus/na en CIL: 7 hombres + esclavo y 3 mujeres + liberta (sin desglosar). Como Castellanus, Montanus, Urbanus, Villanus, Urbicus, Vilicus..., se trata de cognomina indicativos de circunstancias vinculadas al nacimiento y origen, o de una función ejercida
}

nocimiento a la deidad local. La onomástica básica responde a la tipología propia de los peregrini ${ }^{21}$ : Cornelius Cestiif., con la que se designaba también, a raíz de la constitutio Antoniniana, a los que no gozaban plenamente del derecho de ciudadanía romana, i.e., los ciues Latini ${ }^{22}$. Si el gentilicio indígena Aunigainum formaba o no parte integrante de la fórmula onomástica propiamente dicha (Cornelius Vicanus Cestii f.) o era una especie de añadido formal de identificación o asociación, no es posible asegurarlo con certeza ${ }^{23}$.

La falta de praenomen del dedicante, que empieza a notarse en el s. II d.C., apunta más bien hacia el s. III d.C. en que casi desaparece ${ }^{24}$, dejando de ser requisito oficial en la burocracia romana bajo Diocleciano ${ }^{25}$.

Por tratarse de la dedicación de un ara por parte de un particular a una deidad indígena - presumiblemente en agradecimiento-, una datación consular estaría fuera de lugar ${ }^{26}$ al no constituir acto público u oficial, ni tener carácter militar. De las 255 inscripciones en la serie de deidades indígenas,

con anterioridad a la adquisición del cognomen y que éste recuerda, y suelen ser indicativos de antigua condición servil, ibid, 81; id. Onomastic Studies in the Early Christian Inscriptions of Rome and Carthage, Helsinki, 1963, $\mathrm{n}^{\text {s }}$ 94, 219, 441. En la bibliografía de mediados de siglo no se supo precisar que Vicanus es el cognomen del dedicante, y no un mero adjetivo; dan a entender que se trata del cognomen cuantos lo editan con mayúscula, aunque en esto se es en general inconsecuente - bien registrado en el índice de J.M. Blázquez, Religiones primitivas de Hispania, Roma, I, 1962, 263 con ref. a «Erudinus», 211-213-.

21 G. Alföldy, «Le droit de cité et la nomenclature dans l'empire romain», Latomus, 25, 1966, 37-57.

22 Ibid, 37-39, 51-52; id., Noricum, London, 1976, 86, passim; A.N. Sherwin-White, The Roman Citizenship, $2^{\text {a }}$ ed., Oxford, 1973, 268, 274, 311-12, 336, 332-367, 393, passim. Sobre la controvertida cuestión de los derechos de los ciues Latini y nomenclatura vid. ahora A.T. Fear, Rome and Baetica. Urbanization in Southern Spain c. 50 B.C.-A.D. 150, Oxford 1996, 131-169 passim, especialmente 156-161.

${ }^{23}$ Nada de lo mucho (en exceso) que se ha escrito recientemente sobre las gentilitates indígenas («organizaciones suprafamiliares») desmiente esta afirmación; vid. Beltrán (en $M^{a}$ Cruz González, cit. nt. 26), 84-86.

${ }^{24}$ I. Calabi Limentani, Epigrafia latina, Milano, 1968, 158.

25 O. Salomies, Die römischen Vornamen. Studien zur römischen Namengebung, Helsinki, 1987, 204 ss., 362 ss., 391 ss., 409-411 passim (Commentationes Humanarum Litterarum 82, 1987). Societas Scientiarum Fennica.

${ }^{26}$ Hay excepciones: ILER, 988; CIL II 5736, de ámbito astur, -sujetos con nombres indígenas que hacen una dedicación a los Manes, con datación consular (265 d.C.)- vid., entre otros, $\mathrm{M}^{\mathrm{a}}$ Cruz González et al., Las estructuras sociales indígenas del Norte de la Península Ibérica, Vitoria, 1993 (Revisiones de historia antigua 1), 163. CIL XIV 59, de Ostia, lleva datación consular, pero el dedicante es un sacerdote mitraico (L. Calabi, cit. n. 24, $\mathrm{n}^{\circ} 7 \mathrm{~b}$ ); análoga situación en CIL II, 179 (cf. A. García y Bellido, Les religions orientales dans l'Espagne romaine, Leiden, 1967, 49-50). 
$I L E R^{27}$, ninguna lleva datación consular excepto la de Erudino ${ }^{28}$, y lo mismo en la de deidades clásicas indigenizadas - un total de $52{ }^{29}$. Estas inscripciones se caracterizan por su sencillez textual y brevedad; el formulismo es simple. En consonancia con esto, y dentro de su contexto epigráfico, parece apropiado leer $\mathrm{MA}($ ter $) \mathrm{E}(i) \mathrm{V}(s)$ c(um) o(mnibus) s(olvit) o bien $\mathrm{MA}($ ter $) \mathrm{E}(x) \mathrm{V}($ oto $) \operatorname{co}(n) \mathrm{s}(\text { ecrauit })^{30}$, aunque caben otras posibilidades ${ }^{31}$.

La indicación de la fecha (día y mes) en la inscripción tiene interés; el 10 de las calendas de agosto (23 de julio) es día festivo: Neptunalia, que aparecen incluidas en el papiro latino conocido como Feriale Duranum (II, 22) ${ }^{32}$, calendario militar, oficial y de carácter tradicional y estándar, datado entre 224-25 y 235 d.C., probablemente $225-227^{33}$. No es que las Neptunalia fuesen feriae publicae de índole predominantemente militar, sino una de las fiestas de la religión oficial del estado más importantes del año, las cuales desempeñaban un destacado papel en la vida cotidiana ${ }^{34}$. Los dioses del panteón romano iban quedando cada vez más atrás, pero los festejos crecían en popularidad ${ }^{35}$, de ahí que no haya que ver necesariamente una relación directa con Neptuno. Este aspecto de fiesta popular se acentúa más aún al ser añadidos los ludi Neptunalici al calendario del año 354 (Filocalus), que suministra preciosa información sobre las más importantes fiestas y festejos de Roma en el s. IV ${ }^{36}$. Queda, pues, subrayado el carácter imperial de las Neptunalia.

27 Barcelona, 1971, $\mathrm{n}^{\text {os }}$ 704-959. Se descartan las de lectura recompuesta o dudosa.

$28 \mathrm{~N}^{\circ} 851$.

$29 \mathrm{~N}^{\text {os }} 651-703$, y lo mismo en otras partes, e.g., estelas votivas en Calabi Limentani, cit. (nt. 24), $n^{\text {os }}$ 8-14 (págs. 188-195).

${ }^{30}$ Para constituere/consecrare (en dedicatio oficial) hemos tenido en cuenta a D. Fishwick, The Imperial Cult in the West, Leiden, I, 2, 203-213.

${ }_{31} M($ emor) A(nimo grato) $E(x) V($ oto $) \operatorname{co}(n) s$ (ecrauit) $o$ $c($ um) $o$ (mnibus) $s$ (olvit). Debido a un defecto de la fotografía empleada al redactar esta nota no resulta posible ver bien los espacios.

32 Fink et al., «The Feriale Duranum» YClS, VII, 1940 , 11-222, especialmente 147-150; para Neptunalia vid. también G. Wissova, Religion und Kultus der Römer, München, 1902, 250-253; W. Warde Fowler, The Roman Festivals of the Republic, London, 1899, 185-187; P. Herz, ANRW, II, 16.2, 1196.

${ }^{33}$ id., 22-23.

34 id., 148, 167-170.

35 id., 170.

${ }^{36}$ M. R. Salzman, On Roman Time. The Codex-Calendar of 354 and the Rhythms of Urban Life in Late Antiquity, Berkeley, 1990, 119-126, 130-131. Los ludi no eran dies feriae, sino dies festi, y no se vieron afectados por la legislación teodosiana del 389 y 395, lo que facilitó su supervivencia hasta muy tarde - particularidad no tenida en cuenta en la bibliografía tradicional sobre el ara votiva a «Erudino», donde la cuestión queda desenfocada-.
¿Es la fecha de la inscripción meramente casual? En caso afirmativo habría que conceder un índice escaso de romanización oficial, lo que queda desmentido por la manera de indicar la fecha de la dedicatio. Las inscripciones que podemos aducir aquí con fecha del $\mathrm{X} \mathrm{Kal}$. Aug. llevan datación consular y son públicas y militares ${ }^{37}$. En una de ellas (CIL XIII, 6696) un beneficiarius hace una dedicatio a Juno y al Genus loci sin más mención que dicha fecha, sobreentendiéndose en todas que no era necesario más indicación ${ }^{38}$. Se ve igualmente por dicha inscripción cómo no era necesario tampoco que se guardase una relación directa con la deidad titular sino con algunas de ellas, romanas e indígenas, con lo que se subraya el carácter religioso de la dedicatio - un orden de cosas que encontramos en la inscripción cántabra con la dedicación a Erudino-.

En resumen: la datación consular queda descartada en cuanto no apropiada en el caso presente. Las serias dificultades con que tropieza la lectura tradicional del epígrafe la hacen inverosímil, lo que es un factor importante para considerarla errónea. Datable quizá en el s. III d.C., es de interés que la indicación del día y mes coincida con la fiesta de las Neptunalia.

\section{SIGLAS}

Se siguen las de L'Année philologique para publicaciones periódicas y las de L'Année épigraphique para repertorios epigráficos. Historias, prosopografías, Fasti consulares y diccionarios, las siguientes:

CLRE R. S. Bagnall, A. Cameron et al. Consuls of the Later Roman Empire.

FCIR A. DEgRASSI, I fasti consolari dell'impero romano.

ILER J. VIVES, Inscripciones latinas de la España romana.

LRE A. H. M. Jones, The Later Roman Empire 284-602.

PLRE A. H. M. Jones, J. R. Martindale, J. MoRRIS, The Prosopography of the Later Roman Empire.

RuDiz E. DE RugGIERo, Dizionario epigrafico di antichità romane.

${ }^{37}$ Reunidas por W. F. Snyder, «Public Anniversaries in the Roman Empire. The epigraphical evidence during the first three centuries», $Y C l S$, VII, 1940, 282 (págs. 225-317); CIL VI, 100; $C I L$ VI, 793; $C I L$ XIII, 6696; CIL XIII, 11758; $C I L$ XIV, 2258 (siglos II-III d.C.).

38 Similarmente en otros casos, como ILER, 377, con datación consular y fecha de la dedicación el VIII de las calendas de abril (= 25 marzo), sobreentendiéndose Hilaria (cf. CIL I ${ }^{2}, 313$ ). 